\title{
Gambaran indeks massa tubuh, tekanan darah, dan kadar gula darah sewaktu di Dusun Jaten, Sinduadi, Mlati, Sleman, Daerah Istimewa Yogyakarta
}

\author{
Eri Yanuar Akhmad Budi Sunaryo, ${ }^{1,{ }^{*}}$ Rizky Endah Wuningsari, ${ }^{2}$ Sinthya Rasela, ${ }^{3}$ Trivena Putri, ${ }^{4}$ \\ Vincentius Dennis Prabaniarga, ${ }^{4}$ Hamim Majdy Awliya Humani, ${ }^{4}$ Nur Wulan Wijayanti ${ }^{2}$
}

\begin{abstract}
${ }^{1}$ Departemen Keperawatan Dasar dan Emergensi, ${ }^{2}$ Mahasiswa Program Studi IImu Keperawatan, ${ }^{3}$ Mahasiswa Program Studi Gizi Kesehatan, dan ${ }^{4}$ Mahasiswa Program Studi Pendidikan Dokter, Fakultas Kedokteran, Kesehatan Masyarakat, dan Keperawatan, Universitas Gadjah Mada, Yogyakarta, Indonesia
\end{abstract}

\section{Submitted: 27 November 2018 Revised: 30 Desember 2018 Accepted: 31 Desember 2018}

\begin{abstract}
ABSTRAK Penyakit tidak menular (PTM) merupakan penyakit kronis yang tidak ditularkan dari orang ke orang. Setiap tahun, sebanyak 41 juta orang meninggal dunia karena PTM. Di Indonesia pada tahun 19952007 (12 tahun) telah terjadi transisi epidemiologi di mana kematian karena PTM semakin meningkat, sedangkan kematian karena penyakit menular semakin menurun. Angka kejadian PTM di Daerah Istimewa Yogyakarta (DIY) pada tahun 2007-2013 juga mengalami kenaikan. Kami melakukan penelitian untuk mengetahui gambaran indeks massa tubuh, tekanan darah, dan kadar gula darah sewaktu pada warga Dusun Jaten, Sinduadi, Mlati, Sleman, DIY, dalam rangka penapisan awal PTM. Penelitian ini merupakan penelitian retrospektif menggunakan data sekunder yang didapatkan dari catatan pemeriksaan kesehatan pada saat dilaksanakan kegiatan pengabdian kepada masyarakat, 19 Agustus 2018. Data yang diperoleh berupa usia, tinggi badan, berat badan, tekanan darah, dan kadar gula darah sewaktu. Subyek yang diperiksa berjumlah 96 orang, umumnya ( $72,9 \%$ ) termasuk berusia dewasa ( $\geq 20$ tahun sampai $\leq 59$ tahun). Empat puluh tiga persen subyek mempunyai IMT di atas normal. Tujuh puluh persen warga mengalami hipertensi tingkat 1 maupun tingkat 2, dan 5,7\% warga mempunyai kadar gula darah sewaktu $\geq 200 \mathrm{mg} / \mathrm{dL}$. Angka kejadian obesitas, hipertensi, dan diabetes melitus di Dusun Jaten tergolong tinggi sehingga diperlukan edukasi berkelanjutan dan intervensi agar angka kejadian dan komplikasinya dapat diturunkan.
\end{abstract}

KATA KUNCI penyakit tidak menular, indeks massa tubuh; tekanan darah; kadar gula darah sewaktu; Jaten

ABSTRACT Non-communicable diseases (NCDs) are chronic diseases that are not transmitted from person to person. Each year 41 million people die due to NCDs. From 1995 to 2007 (12 years), Indonesia has undergone an epidemiological transition in which deaths from NCD increased, while deaths due to infectious diseases declined. Prevalence of NCDs in the Special Region of Yogyakarta (DIY) has also continued to increase in 2007-2013. We conducted research to obtain a description of body mass index, blood pressure, and random blood glucose in Jaten, Sinduadi, Mlati, Sleman, DIY as early screening for NCDs. This research was a retrospective study using data obtained from the records from a medical check-up done in a community service program on August 19, 2018. Data obtained included age, height, weight, blood pressure, and random blood glucose levels. A total of 96 people were screened. Most (72.9\%) participants were adults (aged $\geq 20$ years to $\leq 59$ years). Results of the screening showed that $43 \%$ of participants were overweight or obese, $70 \%$ had hypertension, and $5.7 \%$ had the random blood glucose of $\geq 200 \mathrm{mg} / \mathrm{dL}$. The percentage of obesity, hypertension, and diabetes mellitus in Jaten are relatively high, indicating a need for long term education and intervention to decrease NCDs prevalence and complications.

*Corresponding author: Eri Yanuar Akhmad Budi Sunaryo

Program Studi Ilmu Keperawatan, Fakultas Kedokteran, Kesehatan Masyarakat, dan Keperawatan, Universitas Gadjah Mada; Jl. Farmako, Sekip Utara Yogyakarta 55281, Indonesia

E-mail: eriyanuar@mail.ugm.ac.id 
KEYWORDS non-communicable disease; body mass index; blood pressure; random blood glucose level; Jaten

\section{Pendahuluan}

Penyakit tidak menular (PTM) merupakan penyakit kronis yang tidak ditularkan dari orang ke orang, ${ }^{1}$ misalnya hipertensi dan diabetes melitus. Di zaman modern, PTM menjadi ancaman di bidang kesehatan. Setiap tahun, sebanyak 41 juta orang meninggal dunia karena PTM, 15 juta di antaranya berusia 30-69 tahun dan lebih dari $85 \%$ kejadian tersebut terjadi di negara berkembang. ${ }^{2}$ Di Indonesia, pada tahun 1995-2007 (12 tahun) terjadi transisi epidemiologi di mana kematian karena penyakit tidak menular semakin meningkat, sedangkan kematian karena penyakit menular semakin menurun ${ }^{3}$. Angka kejadian PTM seperti hipertensi dan diabetes melitus pada tahun 2007-2013 terus mengalami kenaikan. ${ }^{1}$ Di Daerah Istimewa Yogyakarta (DIY) prevalensi hipertensi dan diabetes melitus cenderung meningkat dan berada di atas nilai rata-rata Indonesia. ${ }^{1}$

Hipertensi didefinisikan sebagai tekanan darah sistolik $\geq 140 \mathrm{mmHg}$ dan atau tekanan darah diastolik $\geq 90 \mathrm{mmHg} .{ }^{4}$ Ada beberapa faktor risiko terjadinya hipertensi, antara lain kegemukan, konsumsi makanan tinggi sodium dan rendah potasium, serta kurangnya aktivitas fisik. Hipertensi yang tidak terkontrol dapat menyebabkan komplikasi, misalnya serangan jantung dan stroke.

Selain hipertensi, penyakit yang perlu diperhatikan adalah diabetes melitus. Diabetes melitus adalah penyakit gangguan metabolik menahun akibat pankreas tidak memproduksi jumlah insulin yang cukup atau tubuh tidak dapat menggunakan insulin secara efektif. ${ }^{5} \mathrm{Hal}$ tersebut mengakibatkan kadar gula dalam darah meningkat. Salah satu pemeriksaan yang dapat dilakukan untuk mendiagnosis diabetes melitus adalah dengan pemeriksaan gula darah sewaktu. Seseorang dikatakan menderita diabetes melitus apabila mengalami keluhan yang klasik (poliuria, polidipsi, polifagi, dan penurunan berat badan yang tidak dapat dijelaskan penyebabnya) dan kadar gula darah sewaktu $\geq 200 \mathrm{mg} / \mathrm{dL}^{6}$

Gejala-gejala hipertensi dan diabetes melitus sering tidak khas dan tidak dirasakan oleh penderita sehingga terjadi keterlambatan dalam penegakan diagnosis dan penanganan, yang berakibat pada peningkatan morbiditas dan komplikasinya. Oleh karena itu, perlu dilakukan upaya pencegahan dan deteksi dini hipertensi dan diabetes melitus.

Karena terjadi peningkatan prevalensi hipertensi dan diabetes melitus di DIY, penulis ingin mengetahui gambaran hasil pengukuran tekanan darah, kadar gula darah sewaktu, dan indeks massa tubuh (IMT) pada masyarakat di Dusun Jaten, Sinduadi, Mlati, Sleman, DIY, dalam upaya penapisan dan pencegahan PTM. Dusun tersebut dipilih karena merupakan salah satu wilayah binaan Fakultas Kedokteran, Kesehatan Masyarakat, dan Keperawatan (FK-KMK), Universitas Gadjah Mada (UGM).

\section{Metode}

Subjek pada penelitian ini adalah 96 warga yang datang memeriksakan diri dalam acara pengabdian masyarakat yang digelar pada 19 Agustus $2018 \mathrm{di}$ Dusun Jaten, Sinduadi, Mlati, Sleman, DIY. Data hasil pemeriksaan kesehatan yang meliputi usia, tinggi badan, berat badan, dan tekanan darah diambil secara retrospektif kemudian dianalisis secara deskriptif.

Pengukuran tinggi badan berat badan, dan tekanan darah dilakukan dengan meteran, timbangan, dan sphygmomanometer air raksa yang telah dikalibrasi. Kadar gula darah sewaktu diukur dengan Easy Touch $^{\circ}$ GCU, sesuai dengan petunjuk pemakaian alat.

IMT dihitung dengan membandingkan antara berat badan dalam $\mathrm{kg}$ dengan kuadrat tinggi badan dalam meter. IMT digolongkan dalam empat kategori, yaitu kurus $(<18,5 \mathrm{mg} / \mathrm{dL}$ ), normal $(18,5-24,9 \mathrm{mg} / \mathrm{dL})$, overweight $(25,0-29,9 \mathrm{mg} /$ 
$\mathrm{dL})$, dan obesitas $(>30,0 \mathrm{mg} / \mathrm{dL}) .^{7}$ Tekanan darah dikategorikan dalam 4 kategori, yaitu normal $(<120 /<80 \mathrm{mmHg})$, meningkat $(120-129 /<80$ $\mathrm{mmHg})$, hipertensi tingkat 1 (130-139/80-89 $\mathrm{mmHg})$, dan hipertensitingkat $2(\geq 140 / \geq 90 \mathrm{mmHg}){ }^{8}$ Sedangkan tekanan darah dengan nilai $\geq 180 / \geq 120$ $\mathrm{mmHg}$ termasuk dalam kategori krisis hipertensi. ${ }^{9}$ Analisi univariat dilakukan dan diperoleh distribusi frekuensi pada variabel usia, tekanan darah, gula darah sewaktu, dan indeks massa tubuh. Hasil penelitian disajikan dalam bentuk diagram atau tabel.

\section{Hasil}

Tabel 1 menunjukkan bahwa sebagian besar warga Dusun Jaten yang mengikuti kegiatan pemeriksaan kesehatan adalah orang dewasa ( $\geq 20$ tahun sampai $\leq 59$ tahun) dengan persentase 72,92\%. Lebih dari separuh (52\%) warga tersebut memiliki IMT dalam rentang normal, sedangkan yang mengalami obesitas dan overweight sebanyak 31\% dan $12 \%$. Jadi, terdapat $43 \%$ warga dengan IMT lebih dari normal (Gambar 1).

Gambar 2 menunjukkan hasil pengukuran tekanan darah warga Dusun Jaten yang memeriksakan diri. Sebanyak 36 orang dari 90 orang $(40 \%)$ warga Dusun Jaten memiliki tekanan darah $\geq 140 / \geq 90 \mathrm{mmHg}$, yang termasuk dalam kategori hipertensi tingkat 2. Dua puluh tujuh orang (30\%) menderita hipertensi tingkat 1 dan dua orang warga $(2,2 \%)$ memiliki tekanan darah yang sudah masuk dalam kategori krisis hipertensi. Enam orang warga tidak diperiksa karena tidak bersedia.

Gambar 3 menunjukkan hasil pemeriksaan kadar gula darah sewaktu pada 87 warga Dusun Jaten. Ditemukan bahwa sebanyak 82 orang dari 87 orang $(94,3 \%)$ warga yang menjalani pemeriksaan memiliki kadar gula darah sewaktu $<200 \mathrm{mg} / \mathrm{dL}$. Lima orang warga $(5,7 \%)$ mempunyai kadar glukosa darah sewaktu $\geq 200 \mathrm{mg} / \mathrm{dL}$. Sembilan orang tidak diperiksa karena tidak bersedia.

\section{Pembahasan}

Berdasarkan data dari pengabdian masyarakat
Tabel 1. Distribusi frekuensi dan persentase usia warga Dusun Jaten $(n=96)$

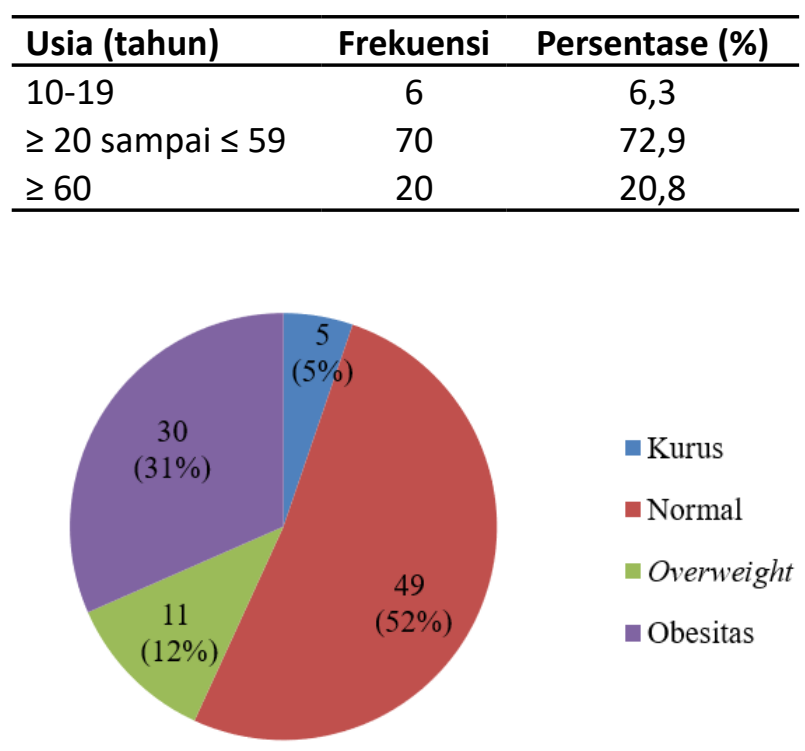

Gambar 1. Distribusi indeks massa tubuh warga Dusun Jaten $(n=96)$

yang dilaksanakan di Dusun Jaten, Sinduadi, Mlati, Sleman, DIY didapatkan hasil bahwa sebagian besar warga yang memeriksakan diri termasuk orang berusia dewasa. Hal ini sesuai dengan data demografi di Indonesia yang menunjukkan bahwa struktur penduduk Indonesia terutama didominasi penduduk muda dan dalam usia produktif. ${ }^{10}$ Pada usia produktif tersebut, diperlukan upaya untuk selalu menjaga dan meningkatkan kondisi kesehatan masyarakat dengan upaya promotif, preventif, kuratif, maupun rehabilitatif, khususnya terhadap PTM seperti hipertensi, penyakit jantung, dan diabetes melitus, yang angka kejadiannya cenderung semakin meningkat pada usia dewasa. ${ }^{1}$ Karena jumlah subjek dalam penelitian ini terbatas dan pemeriksaan dilakukan hanya kepada warga yang datang saat pelaksanaan kegiatan pemeriksaan kesehatan, hasil penelitian ini kemungkinan belum dapat menggambarkan keadaan yang sebenarnya.

IMT merupakan variabel yang mudah digunakan untuk memantau status gizi seseorang. ${ }^{11}$ Pada pemeriksaan IMT di Dusun Jaten, sebanyak $52 \%$ warga memiliki IMT normal. IMT normal menandakan bahwa status gizi dalam batas normal. Manfaat memiliki IMT normal antara 


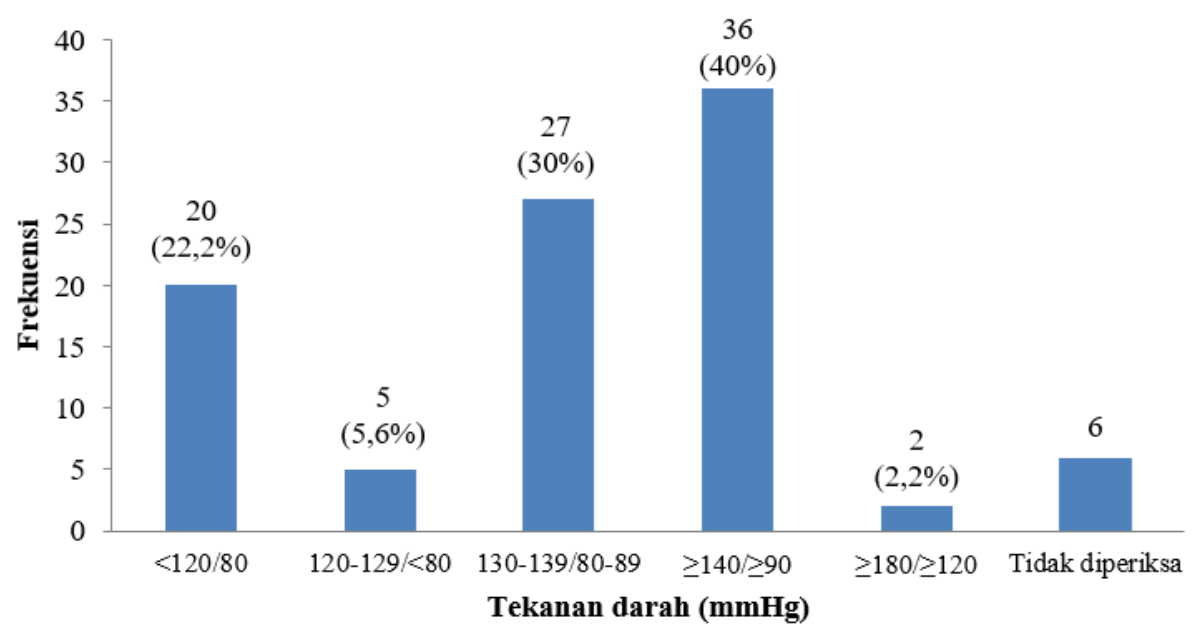

Gambar 2. Distribusi tekanan darah warga Dusun Jaten $(n=96)$

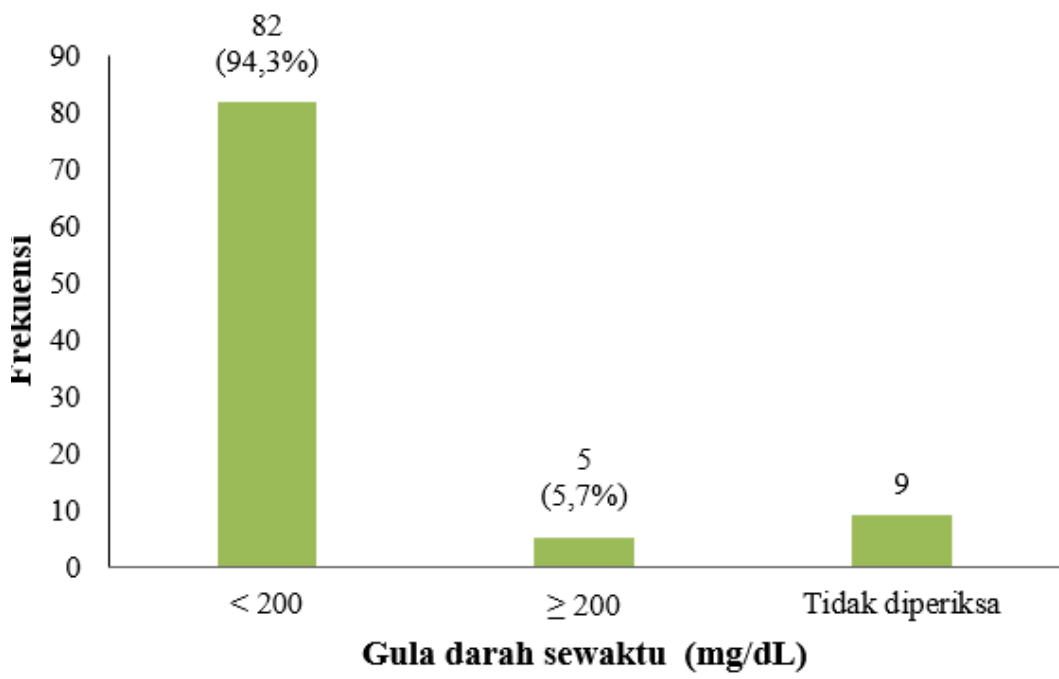

Gambar 3. Kadar gula darah sewaktu warga Dusun Jaten $(n=87)$

lain penampilan lebih baik, lincah bergerak, memiliki risiko PTM, misalnya hipertensi dan diabetes melitus, yang lebih rendah. ${ }^{11}$ Sebanyak 32\% warga memiliki IMT dalam kategori obesitas. Orang dengan IMT kategori obes menunjukkan bahwa status gizinya berlebih atau melebihi batas normal. Obesitas dapat berdampak buruk bagi kesehatan, antara lain mempunyai risiko lebih besar terkena PTM seperti diabetes melitus, hipertensi, dan penyakit jantung. ${ }^{7}$ Obesitas dapat menjadi salah satu faktor risiko hipertensi secara langsung maupun tidak langsung. Secara langsung, obesitas menyebabkan hipertensi karena semakin besar massa tubuh semakin banyak jumlah darah yang beredar sehingga curah jantung semakin meningkat. ${ }^{12}$ Secara tidak langsung, obesitas dapat meningkatkan volume cairan melalui aktivasi sistem saraf simpatis dan sistem renin-angiotensin. ${ }^{13}$ Obesitas juga menjadi salah satu faktor risiko terjadinya diabetes melitus karena pada individu dengan obesitas jumlah asam lemak non-steroid, gliserol, hormon, sitokin, dan penanda proinflamasi meningkat sehingga terjadi resistensi insulin yang menjadikan kadar gula dalam darah meningkat. ${ }^{14}$ Agar IMT kembali normal, perlu dilakukan upaya antara lain berupa olahraga teratur minimal 30-60 menit per hari, mengurangi makanan berminyak dan berkalori tinggi, menghindari minuman 
beralkohol, memperbanyak konsumsi sayur dan buah, serta melakukan penimbangan berat badan secara rutin. ${ }^{11}$ Pada penelitian ini, warga yang mempunyai IMT di atas normal diedukasi untuk memodifikasi gaya hidup agar bisa mencapai IMT yang normal.

Hasil pengukuran tekanan darah terhadap warga Dusun Jaten menunjukkan bahwa sebanyak $63(70 \%)$ orang warga menderita hipertensi, dengan rincian 27 (30\%) orang menderita hipertensi tingkat 1 dan 36 (40\%) menderita hipertensi tingkat 2. Banyaknya warga Dusun Jaten yang menderita hipertensi dapat meningkatkan risiko terjadinya penyakit yang lebih serius atau komplikasi seperti serangan jantung, gagal ginjal kronis, diabetes melitus, penyakit serebrovaskuler, dan stroke. ${ }^{4}$ Hipertensi dapat menimbulkan komplikasi karena tekanan darah tinggi dalam jangka lama dapat menyebabkan pembuluh darah menjadi keras dan tebal, sehingga aliran darah serta oksigen ke jantung akan berkurang dan akhirnya dapat menimbulkan nyeri dada atau serangan jantung. ${ }^{12}$ Tekanan darah yang tinggi juga dapat menyebabkan pembuluh darah menjadi lemah dan membengkak sehingga dapat terjadi aneurisma. Apabila aneurisma tersebut pecah maka dapat menyebabkan stroke. ${ }^{13}$

Hipertensi yang terjadi pada sebagian besar warga di Dusun Jaten dapat diminimalisir atau dikontrol dengan cara mengkonsumsi obat antihipertensi sesuai dosis yang disarankan dokter, rutin memeriksakan tekanan darah, mengurangi konsumsi garam, melakukan aktivitas fisik minimal 30-60 menit per hari, tidak merokok, mengurangi konsumsi alkohol, mempertahankan berat badan normal, serta mengurangi dan mengelola stres. ${ }^{4}$ Edukasi mengenai gejala hipertensi dan cara pencegahannya perlu terus dilakukan agar angka kejadian hipertensi berserta komplikasinya dapat diturunkan. Pada penelitian ini, warga yang mengalami hipertensi diedukasi dan dirujuk ke puskesmasterdekat agar mendapatkan penanganan yang tepat dan termonitor dengan baik.

Pada pemeriksaan kadar gula darah sewaktu, sebanyak 82 orang dari 87 orang $(94,3 \%)$ warga Dusun Jaten memiliki kadar gula darah kurang dari
$200 \mathrm{mg} / \mathrm{dL}$. Hal ini menandakan bahwa sebagian besar warga Dusun Jaten tidak mengalami diabetes melitus. Seseorang dikatakan menderita diabetes melitus apabila mengalami gejala klasik dan memiliki kadar gula darah sewaktu $\geq 200 \mathrm{mg} / \mathrm{dL}^{14}$ Selain pemeriksaan kadar gula darah sewaktu, terdapat beberapa pemeriksaan lain yang dapat digunakan untuk membantu menegakkan diagnosis diabetes melitus, yaitu pemeriksaan kadar glukosa puasa, kadar glukosa puasa setelah tes toleransi glukosa dengan beban glukosa 75 gram, dan kadar HbA1c. ${ }^{6}$ Pada penelitian ini, gejala klasik diabetes melitus tidak ditanyakan dan hanya dilakukan pemeriksaan kadar glukosa darah sewaktu karena kegiatan yang dilakukan hanya dimaksudkan untuk penapisan awal. Lima orang warga $(5,7 \%)$ yang memiliki kadar glukosa darah $\geq 200 \mathrm{mg} / \mathrm{dL}$ diberi edukasi untuk datang ke puskesmas terdekat untuk pemeriksaan dan pengobatan lebih lanjut.

Gejala klasik diabetes melitus meliputi poliuria (sering kencing), polidipsi (sering haus), polifagi (banyak makan), dan berat badan menurun tanpa penyebab yang jelas. Masyakarat perlu mengetahui tanda dan gejala diabetes melitus secara dini, karena diabetes melitus yang tidak terkontrol dapat menimbulkan berbagai komplikasi. Komplikasi yang dapat timbul karena diabetes melitus antara lain yaitu penyakit jantung, stroke, neuropati diabetikum, retinopati diabetikum, dan gagal ginjal. ${ }^{5}$ Cara untuk menjaga agar gula darah tetap normal yaitu dengan diet sehat yang mengandung sedikit lemak jenuh namun tinggi serat larut, menyesuaikan jumlah asupan kalori dengan berat badan ideal, menjaga berat badan tetap ideal, melakukan aktivitas fisik selama 30-60 menit per hari, dan berhenti merokok. ${ }^{6}$

\section{Kesimpulan}

Pada kegiatan pengabdian masyarakat yang dilakukan di Dusun Jaten, terdapat 96 orang warga yang memeriksakan diri, sebagian besar termasuk dalam usia dewasa. Empat puluh tiga persen subjek mempunyai IMT di atas normal. Tujuh puluh persen warga mengalami hipertensi tingkat 1 maupun tingkat 2, dan 5,7\% warga mempunyai kadar 
gula darah sewaktu $\geq 200 \mathrm{mg} / \mathrm{dL}$. Angka kejadian obesitas, hipertensi, dan diabetes melitus di Dusun Jaten tergolong tinggi sehingga diperlukan edukasi berkelanjutan dan intervensi agar angka kejadian dan komplikasinya dapat diturunkan.

\section{Ucapan terima kasih}

Ucapan terima kasih kami berikan kepada Tim Community and Family Health Care-Inter Professional Education (CFHC-IPE), Fakultas Kedokteran, Kesehatan Masyarakat, dan Keperawatan (FK-KMK), Universitas Gadjah Mada (UGM), warga Dusun Jaten yang telah bersedia berpartisipasi dalam kegiatan ini, serta kepada pihak-pihak lain yang telah membantu berlangsungnya kegiatan ini sehingga dapat berjalan dengan lancar.

\section{Daftar pustaka}

1. Kementerian Kesehatan Republik Indonesia. Riset kesehatan dasar 2013. Jakarta: Badan Penelitian dan Pengembangan Kementerian Kesehatan Republik Indonesia; 2013.

2. World Health Organization. Noncommunicable diseases. World Health Organization; 2018.

3. Kementerian Kesehatan Republik Indonesia. Penyakit tidak menular. Jakarta: Buletin Jendela Data dan Informasi Kementerian Kesehatan Republik Indoensia; 2012.

4. Soenarta AA, Erwinanto, Mumpuni ASS, Barack R, Lukito AA, Hersunarti $N$, et al. Pedoman tatalaksana hipertensi pada penyakit kardiovaskular. 1st ed. Perhimpunan Dokter Spesialis Kardiovaskular Indonesia; 2015.

5. Kementerian Kesehatan Republik Indonesia. Situasi dan analisis diabetes. Jakarta: Pusat Data dan Informasi Kementerian Kesehatan Republik Indonesia; 2014.

6. Soelistijo SA, Novida H, Rudijanto A, Soewondo $P$, Suastika K, Manaf A, et al. Konsensus pengelolaan dan pencegahan diabetes melitus tipe 2 di Indonesia 2015. 1st ed. Pengurus Besar Perkumpulan Endrokinologi Indonesia; 2015.
7. Centers for Disease Control and Prevention. About adult BMI [Internet]. Centers for Disease Control and Prevention; 2017 [updated 2017 Aug 29]. Available from: https://www.cdc. gov/healthyweight/assessing/bmi/adult_bmi/ index.html

8. Himmelfarb CD, Stafford RS, D PH. 2017 ACC / AHA / AAPA / ABC / ACPM / AGS / APhA / ASH / ASPC / NMA / PCNA guideline for the prevention, detection, evaluation, and management of high blood pressure in adults. 2018;71(19).

9. Sheps SG. Hypertensive crisis: What are the symptoms? 2017.

10. Yudianto, Budijanto D, Hardhana B, Soenardi TA. Profil kesehatan Indonesia 2014. Jakarta: Kementerian Kesehatan Republik Indonesia; 2015.

11. Kementerian Kesehatan Republik Indonesia. Pedoman praktis memantau status gizi orang dewasa. Jakarta: Kementerian Kesehatan Republik Indonesia; 2001.

12. Sulastri D, Elmatris, Ramadhani R. Hubungan obesitas dengan kejadian hipertensi pada masyarakat etnik Minangkabau di Kota Padang. Majalah Kedokteran Andalas. 2012;36(2).

13. Jiang S-Z, Lu W, Zong X-F, Ruan H-Y, Liu Y. Obesity and hypertension. Exp Ther Med. 2016;12(4):2395-9.

14. Al-Goblan AS, Al-Alfi MA, Khan MZ. Mechanism linking diabetes melitus and obesity. Diabetes Metab Syndr Obes. 2014:7;587-91.

15. World Health Organization. Hypertension. World Health Organization; 2011.

16. Bell K, Twiggs J, Olin BR. Hypertension: The silent killer: Updated JNC-8 Guideline Recommendations. 2015.

17. American Diabetes Association. Standards of medical care in Diabetes - 2018 abridged for primary care providers. American Diabetes Association; 2017. p. 1-24. 